\title{
Tuition-Waiver Policies for Older Learners in University Courses: Past Practices, Current Developments and Future Prospects
}

\section{GORDON THOMPSON}

The University of Saskatchewan

\section{ABSTRACT}

Over the past 30 years, many universities in Canada and the United States have introduced tuition-waiver policies for older adults. This article reviews the literature describing the development and outcomes of these programs. Although several national surveys of tuition-waiver programs have been reported in the United States, none have previously been reported for Canadian universities. This article reports the results of the first such survey. Despite the widespread availability of tuitionwaiver programs in Canada and the United States, it is clear that such programs have failed to attract significant numbers of older learners. The paper examines the causes and the implications of this failure.

\section{RÉSUMÉ}

Au cours des 30 dernières années, plusieurs universités canadiennes et américaines ont adopté de nouvelles politiques dispensant les frais de scolarité pour les aînés. Cet article fait le survol de la littérature décrivant le développement ainsi que les résultats de tels politiques et programmes. Bien qu'on signale plusieurs enquêtes nationales aux ÉtatsUnis concernant les programmes dispensant les frais de scolarité, on ne peut rapporter une enquête similaire visant les universités canadiennes. 
Malgré l'accessibilité générale aux programmes canadiens et américains dispensant les frais de scolarité, il est clair que de tels programmes n'ont pas attiré un nombre important d'apprenants âgés. Ce document examine les causes et les conséquences possibles d'un tel échec.

\section{INTRODUCTION}

Universities in Canada and the United States introduced tuitionwaiver policies for older adults commencing in the 1960s and 1970s. Many universities in both countries adopted these policies, and in the United States, many state legislatures enacted tuition-waiver legislation to permit older adults to enroll in publicly supported institutions of higher education with the tuition fees either being waived altogether or reduced. Today, the majority of Canadian universities and the majority of public universities in the United States provide tuition-waiver programs for older adults. Nonetheless, in Canada, there has been a growing trend over the past decade to discontinue these policies or at least to reduce them. What has been the history of these policies? Why were they implemented and have they been successful? What are the recent developments relating to the discontinuation or reduction in the benefits provided by these policies? What considerations should guide universities in tuition-waiver policies and practices? Unfortunately, the subject of tuition-waiver policies has received little attention, especially in Canada. Most of the literature concerning this topic was published in the 1970 s and 1980s and it has received relatively little attention in the past decade. This is unfortunate for several reasons:

1. Research conducted in the 1970s and 1980s indicated that disappointingly small numbers of older learners were enrolling and taking advantage of tuition-waiver programs.

2. Some studies have proposed ways in which universities and colleges could attract larger numbers of older learners to tuition-waiver programs but there is some evidence that university administrators see little advantage in doing so when these students generate no revenue for the institution. 
3. There is some evidence, at least in Canada, that over the past decade a significant number of universities have rescinded their tuition-waiver policies or at least restricted those eligible for such benefits. Changes to such policies should be informed by more research on tuition-waiver policies and in the light of emerging demographic and social trends.

This paper reviews the published literature on university tuitionwaiver policies for older adults. It reports the results of the first national survey undertaken of tuition-waiver policies in Canadian universities. Finally, it examines some of the options that universities and colleges should consider in determining whether, and how best, to respond to the needs of older adults.

\section{REVIEW OF RELATED LITERATURE}

\section{The introduction of tuition-waiver programs}

The University of Kentucky was the first institution of higher education in the United States to offer a tuition-waiver program for older adults (Danner, Danner \& Kuder, 1993). Initiated in 1964, it has served as a model for similar programs elsewhere. The program allows persons over the age of 65 to register for regular degree-credit courses with the normal tuition fees being waived. It also permits persons who are 60 or older to register without cost for a range of classes specifically designed for older learners. In the 1970s, many state legislatures in the United States enacted some form of centralized authorization allowing senior citizens to attend regular degree-credit courses at free or reduced tuition. Chelsvig and Timmerman (1979) noted that tuition-waiver programs expanded rapidly in the 1970 s and they pinpoint 1974 as the year in which the most dramatic increase occurred. Long and Rossing (1978) also pointed to 1974 and 1975 as the years in which such state action peaked. By 1979, a total of 1093 higher education institutions in the United States had adopted free or reduced tuition policies for older adults (Chelvig \& Timmerman, 1982). This represented nearly one in every three higher education institutions in the country. 
While these tuition-waiver programs adopted the general character of the program at the University of Kentucky, there were some significant differences among them. Long and Rossing (1979) observed that some state-initiated policies included authority to waive tuition but did not require their higher education institutions to do so, whereas others made tuition-waiver mandatory. Most policies provided for full tuition-waiver but some provided for only reduced tuition. They identified a number of other differences. All tuition-waiver policies specified a minimum age for eligibility - but some specified 60, others 62 and still others 65 . Most policies permitted tuition-waiver students to register for credit (or audit) but three would only permit audit status. Of special note, most programs specified that those eligible for tuition-waiver would only be permitted to register where places remained available after all regular-tuition students had been accommodated, but three had no such restriction.

Where do things stand in regard to tuition-waiver policies today? Manheimer, Snodgrass and Moskow-McKenzie (1995) provided the most recently published comprehensive report of the status of tuition-waiver programs in the United States. They reported that in 1995, 38 states and the District of Columbia had tuition-waiver policies based upon age. Several of these states also imposed a requirement for demonstrated financial need. Among the twelve states with no legislation or state policy to waive or reduce tuition for older adults, were six states in which individual universities or colleges had adopted such policies. Accordingly, in only six states (Alabama, Arizona, California, Colorado, Iowa and Nebraska) were there no age-based tuition-waiver programs in place.

Why were tuition-waiver policies created and have they been effective? Romaniuk (1984) proposed that the adoption of tuition-waiver policies may be due, at least in part, to recommendations that arose from the 1971 White House Conference on Aging. Nonetheless, she observed that the reasons for the growth of such policies have never been documented. Her review of state legislation relating to tuition-waiver policies identified three major assumptions which appeared to provide the underlying rationale for their development (p. 122):

1. Older people have the ability and desire to seek additional knowledge. 
2. There are currently barriers to participation in institutions of higher education for older persons.

3. The major barrier to participation is financial.

If these assumptions are correct, it is reasonable to expect that the wide-spread introduction of tuition-waiver policies would result in a significant increase in the number of older learners enrolling in higher education institutions. Has such an increase occurred? While the question is straightforward, the answer is not.

There are no recent and comprehensive nation-wide reports in either Canada or the United States which detail the number and characteristics of older persons who have participated in tuition-waiver programs. Some studies in the United States have reported enrolment trends related to tuition-waiver policies within individual institutions. For example, Danner et al. (1993) reported that over the first 25 years of the Donovan Scholars Program at the University of Kentucky, a total of 942 individuals enrolled. They indicated that while the number of participants has increased since the program's inception, the rate of increase has been slow (1983, p. 235). Romaniuk (1983) analyzed the impact of tuitionwaiver policies upon older adults in higher education institutions in Virginia. She reported that the number of participants in tuition-waiver programs was small and that they constituted a minority of all older adults in Virginia's higher education institutions. Indeed, only $30 \%$ of the registrants aged 60 or older in Virginia's higher education institutions were in the tuition-waiver programs. Earlier reviews of tuition-waiver programs concluded that enrolment in tuition-waiver programs has been modest (Long, 1983; Moyer \& Lago, 1987). More recently, Manheimer et al. (1995) and Eisen (1998) concluded that despite the widespread availability of such programs, relatively few older adults have enrolled using the tuition-waiver policy. On the other hand, it should be noted that enrolments of older learners dropped dramatically in those instances where tuition-waiver programs were discontinued. Manheimer et al. identified community college campuses in California and North Carolina as examples where this occurred (1995, pp. 32-33). In addition, Perkins and Robertson-Tchabo (1981) reported that the University of Maryland introduced a tuition-waiver program in 1977 and experienced a 340\% 
increase in the enrolment of students aged 60 and older. Nonetheless, it appears that the general conclusion is that tuition-waiver programs have not been successful in attracting significant numbers of older learners. What are the reasons for such failure?

\section{Barriers to participation}

Cross (1981) identified three types of barriers to participation in learning activities: situational, institutional and dispositional. Situational barriers are those arising from one's situation in life at a given time, such as lack of adequate financial resources. Institutional barriers refer to those policies or practices that exclude or frustrate participation in educational activities, such as inconvenient timetables or class locations. Dispositional barriers include attitudes and self-perceptions such as lack of confidence in one's ability to learn. This typology provides a useful framework for examining barriers to participation by older learners.

The situational barrier of cost has been examined in a number of studies. As Romaniuk (1984) noted, tuition-waiver programs appear to be premised upon the assumption that the major barrier to participation of older learners is the cost. But this assumption is questionable. Moyer and Lago (1987) reviewed studies which examined the impact of cost as a barrier to participation. They reported the following conclusions:

1. Cost is not likely to be mentioned as a major barrier to participation among older adult learners.

2. Cost is not likely to be mentioned as the major incentive among older adult learners either.

3. Program administrators have varying views of the importance of tuition-waiver in reducing the cost barrier for older adult learners. Moyer and Lago cited two surveys which revealed very divided opinions on the issue.

Danner et al. (1993) surveyed participants in the Donovan Scholars Program regarding their reasons for enrolling in the program. They reported that free tuition was a moderately important reason for enrolling but other motives were of greater importance. A second situational barrier which has been cited in some studies is time constraints (A Report, 2001; Lamdin \& Fugate, 1997). Other situational barriers which have 
been identified include physical handicap (Lamdin \& Fugate, 1997) and lack of support from family (Scala, 1996).

Institutional policies and practices may contribute to reduced levels of participation. Graney and Hays (1976) surveyed a group of persons aged 62 and older who identified informational barriers as being of greatest concern. They proposed that increased public information and outreach programs were needed, especially ones which provided information about how to (re)enter the educational system, and by reports describing the successful experiences of older learners in higher education. Long (1980) surveyed tuition-waiver program practices and reported considerable variability in the extent to which they were promoted. He reported that a majority of respondents indicated that little or no effort was made to promote the programs. Heisel, Darkenwald and Anderson (1981) observed that older adult learners are underrepresented in continuing education programs. They argued that educators who want to recruit greater numbers of older learners must abandon the:

...conventional marketing approach that focuses on the individual consumer of services and must employ more personal 'social linkage' strategies to overcome the psychosocial and situational barriers that are so formidable for this group. (p. 239)

They proposed that this would necessitate working with groups and organizations in the community with which older adults are affiliated. Danner et al. (1993) reported that nearly all of the Donovan Scholars they surveyed were recruited to the program through their association with the University or contact with others in the program. They proposed an "aggressive outreach program" was needed to recruit more participants (p. 236). Other studies have proposed that special advisory and support services are needed to attract older learners and to promote their success and retention. Chelsvig and Timmerman (1982) surveyed higher education institutions which provided tuition-waiver programs to determine the adequacy of support services. They found that there existed a general lack of services such as simplified registration, counseling, special programs, organized older student groups, and outreach activities. They argued that tuition-waiver programs lacking such supports will 
likely be "radically underutilized" (p. 274). Moyer and Lago (1987) proposed that access to academic counselors should be regarded as integral to tuition-waiver programs as well as alternative modes of delivery which reduce the barriers to access such programs. They warn that existing tuition-waiver programs risk being seen as "window dressing" if they fail to provide appropriate services for the older learner. More recently, Scala (1996) studied the experiences of older learners and identified several issues which she proposed could usefully guide higher education planners and administrators in order to make their programs more accessible to older people. She observed that a number of students experienced some academic difficulties and proposed workshops for older learners that would improve their study skills. She also noted that a number of older learners faced challenges in adjusting to campus life and in integrating their studies with family and time pressures. She proposed that it would be helpful to have a separate orientation for older learners including workshops on time and stress management to reduce adjustment problems. Finally, she noted that it would be desirable to have a gathering place or lounge for seniors to assist them to meet each other. A final institutional barrier for older learners concerns problems associated with transportation, parking and classroom access. Educational programs seeking to attract older learners must be readily accessible (Hooper, 1981; Kingston, 1982; Kingston \& Drotter, 1983; Moore \& Piland, 1994; Scala, 1996). Moore and Piland (1994) also recommended the creation of a seniors advisory committee to assist college administrators with educational and physical environmental planning.

Dispositional barriers to participation in learning activities cited by older adults include lack of motivation and lack of confidence in one's learning ability (Lamdin \& Fugate, 1997). Scala (1996) identified feeling out of place among younger students as an additional dispositional barrier. Indeed, Manheimer (1998) stated that most older adults would prefer to learn with their peers in age-segregated programs rather than be in classes with younger students, although two studies have reported the opposite (Danner et al., 1993; Hooper, 1981). Interestingly, Johnstone and Rivera (cited in Cross, 1981) reported that older adults were more likely to cite dispositional barriers whereas younger adults were more 
constrained by situational barriers. A further consideration is warranted. Concerns about barriers to participation are premised upon an expectation that their removal would likely lead to active involvement. But another explanation for the low rates of participation by older learners is a lack of interest (Lamdin \& Fugate, 1997).

Clearly, many of these barriers, including targeted marketing and information services, special student services and improved classroom accessibility, are ones which can be overcome. In most cases however, the means to do so will require additional institutional funding. Regrettably, there is little incentive for college and university administrators to commit such resources (Manheimer et al., 1995; Moyer \& Lago, 1987; Romaniuk, 1983).

In light of these barriers and their constraining effects upon older learners, what do we know about the characteristics of those older learners who do participate in higher education?

\section{Characteristics of older learners}

A number of studies have reported upon the characteristics of older learners in higher education. One of the first and most compelling findings is that a disproportionately small number of older adults participate in higher education in comparison with other age groups (A Report, 2001; Bynum \& Seaman, 1993; Dickenson et al., 1990; Lamdin \& Fugate, 1997; Manheimer et al., 1995, Merriam \& Caffarella, 1999; Peterson \& Masunaga, 1998).

Similar findings are reported elsewhere in the world. For example, Midwinter (1983/84) reported that in England and Wales "...the numbers of older people engaged in adult and continuing education are appallingly few..." (p. 10). Minichiello (1992) reported that older people in Australia are underrepresented at all levels of the educational system. Thång and Wärvik (2000) reported that in Sweden, middle-aged and older people are underrepresented in adult education programs. Tikkanen (1998) found that older persons were less likely to participate in adult education but he argued that there are important interactions with previous levels of education which make the age-participation relationship more complex than previously reported. Indeed, level of previous education is another factor which has been consistently associated with participation of older adults 
in higher education. Older adults who participate in educational activities tend to be those with a higher level of previous education (A Report, 2001; Dickenson et al., 1990; Lumdin \& Fugate, 1997; Martin \& Lyday, 1997; Merriam \& Caffarella, 1999; Scala, 1996). This finding was also reported to apply to the participants in the tuition-waiver program at the University of Kentucky. An examination of the characteristics of the "Donovan Scholars" over the twenty-five year period since the program's inception (1964-1989) revealed that they are "...predominantly white female professionals (mostly teachers) who have come back to the University to supplement and extend their previously high levels of education" (Danner et al., 1993, p. 235). Insofar as tuition-waiver programs are concerned, this finding is hardly surprising. If these programs tend to be poorly promoted, generally fail to provide supplementary student services, and are typically offered in unfamiliar locations with limited accessibility, they are not likely to attract people who have had little or no prior association with higher education institutions.

From this brief review of the literature, it is clear that conclusions relating to tuition-waiver programs must be made with caution. Nonetheless, the following generalizations seem warranted:

1. Tuition-waiver programs are widespread in post-secondary institutions in the United States.

2. Despite the widespread availability of such programs, they have attracted a modest number of participants.

3. Most older adults who do participate in higher education have higher levels of previous education than nonparticipants.

4. The reasons which prompted the widespread introduction of tuition-waiver programs are not well documented but there is some evidence that institutions adopting these policies were seeking to promote participation by older adults for whom the costs of regular tuition would have been a barrier.

5. Even among those institutions that have introduced tuitionwaiver programs, few have adopted student services tailored to the needs of older adults. It is conceivable that the provision of 
such services might have increased the level of participation by older adults in these programs.

These conclusions are drawn from literature relevant to institutions in the United States. But what is the situation in Canada? Regrettably, there are no published reports that provide a comparable outline of the tuition-waiver policies of Canadian universities. Accordingly, a survey of such policies was undertaken and is presented below.

\section{SURVEY OF CANADIAN UNIVERSITIES TUITION-WAIVER POLICIES}

There are 92 member institutions of the Association of Universities and Colleges of Canada (AUCC). During 2001, the websites of each of these institutions were examined to locate the institutional policy relating to tuition practices for senior citizens. A total of 46 members of the AUCC were found to have websites which described such policies. The remaining institutions were contacted by e-mail to ascertain their policies. In each case, the enquiry was directed to either the Office of the Registrar or the Office of the Dean/Director of Continuing Education. These inquiries resulted in information being provided by an additional 41 institutions on their tuition policies for older adults. In total therefore, the survey determined the policies of 87 AUCC member institutions regarding their tuition-waiver policies for older adults. This represents a response rate of $95 \%$. Respondents were asked whether they had a tuition-waiver policy for older adults and, if so, what were the benefits and conditions defined by the program.

A total of 62 of the 87 institutions currently have tuition-waiver programs. Of these, 52 are based solely upon an age-based eligibility and 10 have both an age criterion and a requirement of demonstrated financial need. There was a significant level of uniformity in the policies reported by these institutions. Most policies specify 65 as the minimum age to qualify for tuition-waiver but some specify age 60 . The University of Winnipeg specifies age 65 , or age 60 if unemployed. The University College of Cape Breton specifies age 65, or age 60 if retired. Some institutions limit the number of courses covered by the tuition-waiver policy which may be taken each academic term. For example, Redeemer 
University College allows a maximum of one course per term. A number of institutions have special restrictions on which credit courses are covered (typically all non-credit courses are excluded from the policy). For example, many specify that the tuition-waiver policy does not apply to distance education courses. Further, the tuition-waiver policy generally only applies where places remain available at the close of the normal registration period. There is considerable variability in the level of financial support provided. Most institutions with a tuition-waiver policy waive the entire cost of tuition fees but others provide only partial tuition-waiver. For example, one institution provides only a $10 \%$ reduction in the tuition fees.

In summary, it appears from the survey that the situation in Canada is comparable to that in the United States. Tuition-waiver policies are widely available but are defined by similar parameters as those in the United States. Of particular interest to the present study however, is the recent trend among Canadian universities to eliminate tuition-waiver programs.

The survey identified 7 institutions which had previously adopted tuition-waiver policies for older adults but which had rescinded these policies within the last decade. Five of these institutions rescinded these policies since 1998. An additional 12 AUCC member institutions have either significantly reduced their tuition-waiver benefits or have introduced a needs-based requirement to qualify for the tuition-waiver. In some of these institutions there is a means test applied before the waiver is granted or the bursary awarded but in other cases it is automatically awarded following a declaration of need. It is important to recognize that some older learners are reluctant to apply for such financial support and might be discouraged from registering. Appendix 1 lists the institutions which have rescinded or restricted their tuition-waiver policies. In each case, a brief description is provided of the previous tuition-waiver policy and the current policy. The 19 institutions listed represent $21 \%$ of all AUCC members. In short, there has been a significant reduction in the provision of tuition-waiver programs by Canadian universities in recent years and it is possible that this is part of a developing trend which could become more widespread. No similar analysis has been recently published for higher education institutions in the United States although 
isolated examples have been reported. For example, Manheimer et al. (1995) reported that Wisconsin rescinded their tuition-waiver policy in 1991. Long and Rossing (1979) reported that California had adopted a two-year tuition-waiver pilot project in 1975 at just two state universities but Manheimer et al. (1985) listed California as one of the six states in which there was no provision for tuition-waiver for older adults. Presumably, the tuition-waiver policy in California was not extended beyond the pilot project phase. Chelsvig and Timmerman (1982) reported that their survey identified ten institutions which "...either had withdrawn the tuition policy in effect at the time of the 1977 survey or no longer existed..." (p. 270).

The decision by a number of institutions (and states) to rescind tuition-waiver policies is hardly surprising. As noted previously, studies in the United States have consistently reported that tuition costs have not been found to be a significant deterrent, nor has tuition-waiver been shown to be a significant incentive for older learners. In addition, tuition costs have increased dramatically over the past several decades since the widespread adoption of tuition-waiver policies for older adults. Recent reports in both Canada and the United States have emphasized the extent to which access to higher education is being increasingly constrained for needy students while debt loads incurred by students are growing (see for example, Brownstein, 2000; Burd, 2001; Education moving, 2000; Government funding, 2000; Hebel, 2001). In light of the increasing financial pressures being faced by younger students it should come as no surprise that tuition-waivers for older students are coming under increasing scrutiny. This is especially true in the light that a significant number of older adults who do enroll have high levels of prior education, and financial considerations do not appear to constrain their participation. Perhaps it is time to review the need for tuition-waiver policies for older adults.

According to Manheimer (1998), tuition-waiver policies evolved during a time when there existed a "social welfare orientation" toward older adults. This orientation focussed on the need to assist older adults to cope successfully with the problems they faced as they grew older. Education was seen as a means to ameliorate these problems. Manheimer also noted that the 1960s and 1970s was a period when a 
significant proportion of older adults lived below the poverty level and that one outcome of the 1971 White House Conference on Aging was a concern to make education accessible to older adults at little or no cost. The tuition-waiver policy was conceived therefore in a culture of wellintentioned accommodation. Almost without exception, no additional funds were allocated to implement tuition-waiver policies (Romaniuk [1983] reported that two states allowed institutions to count tuitionwaiver students in their FTE calculations). Reciprocally, the tuitionwaiver-programs were premised upon the assumption of no new costs. No additional classes would be offered to accommodate tuition-waiver registrants. Rather, they would be allowed to claim any places remaining available after all tuition-paying students had been accommodated - in other words, they could claim seats which would have gone empty otherwise. As noted previously, resources were generally not provided to promote awareness of tuition-waiver programs nor to provide supplementary student services for older learners. But as Lamdin and Fugate (1997) observed, there is something degrading about the secondclass status that accompanies older adults being allowed to take the places remaining after "regular" students have been accommodated. In the survey of Canadian universities, one respondent indicated that at her university:

Many of the senior citizens did not think they needed the financial assistance, and ended up donating the money back to the University. Indeed, some just didn't like being tagged 'senior citizens', and felt that as nice as the gesture was, it was a sort of discrimination based on age which assumed that if you are 60 or older, you were without means to pay for your own courses. (J. V. Fleet, personal communication, November 5, 2001)

While this survey provides a useful glimpse of tuition-waiver policies in Canada it suffers from serious limitations. It provides no statistical data describing participation rates. It provides no information on the reasons which lead to the discontinuation of tuition-waiver policies and provides no information on the institutions which may be seriously contemplating similar changes in the near future. It provides no information 
on the experiences of students who have participated in the tuitionwaiver programs. In short, much more research in this area is warranted.

If tuition-waiver policies were intended to significantly increase the participation rates of older learners, and especially those who would have otherwise been deterred by the cost of tuition, they do not appear to have been a success. So why not simply rescind these policies as some institutions have recently done?

\section{EXAMINING THE OPTIONS}

Universities and colleges which have age-based tuition-waiver policies are faced with several choices. They can maintain the status quo. They can rescind their tuition-waiver policy altogether. Or, they can restrict the tuition-waiver policy in some way such as limiting it to those with financial need. As we have seen from the survey of Canadian universities all three options have been exercised. What considerations should guide this decision? Chief among them are the following.

The limited research that is available suggests that tuition-waiver policies have not achieved their (apparent) objectives. They do not appear to have attracted significant numbers of older learners, and more importantly, they do not appear to have attracted persons for whom regular tuition fees would have been a serious deterrent. In light of the anticipated enrolment pressures from increasing numbers of younger students and the growing burden of tuition fees borne by these younger students, it is difficult to justify the continued availability of tuition-waiver programs for older adults.

Current projections suggest that the number of persons aged 65 and older will increase dramatically in the next several decades. In both Canada and the United States, it is expected that this population cohort will double between now and 2030 and will by then represent approximately $20 \%$ of the population (A growing population, n.d.; Facts about older Americans, n.d.). Seniors are also better educated today and this trend is expected to continue. For example, Statistics Canada reported that in 1996 only $8 \%$ of Canadians aged 65 and older had a university degree, compared with $17 \%$ of persons aged 25 to 64 (Novak \& 
Campbell, 2001, p. 230). This trend to greater participation by younger adults in university education is especially important since level of prior education is associated with an increased likelihood of subsequent participation in educational programs. For example, Statistics Canada has recently reported that the odds of participating in a learning activity for Canadians with a university degree were 7.5 times greater than for those without a high school diploma (A Report on Adult Education, 2001, p. 18). These factors suggest a substantial increase in demand by older learners could occur over the next three decades.

Current tuition-waiver policies provide little incentive for educational institutions to actively recruit older learners or to introduce supplementary student services for older learners. So long as tuition-waiver policies generate no revenue for the institution they are not likely to adopt such strategies. The absence of such services leaves institutions open to criticism that they are not adequately responsive to the needs of older adults.

The outright elimination of tuition-waiver policies should be approached with some caution as such actions might inadvertently send the unintended message that the institution does not welcome older learners. This would be unfortunate. Older adults benefit from the opportunity to participate in educational programs and studies have confirmed the positive contributions they make to the mixed-age classroom (Bishop-Clark \& Lynch, 1995; Hays \& Hays, 1996). Moreover, older learners may be seen as potential donors if they have been well served by the institution (Martin \& Lyday, 1997).

Apart from participation in degree-credit tuition-waiver programs, it is important to recognize that many universities provide a range of noncredit educational programs sponsored by their continuing education unit and some of these programs are specifically designed for older learners. The vast majority of these programs are excluded from tuition-waiver programs and instead are offered on a cost-recovery basis. As Manheimer et al. (1995) noted, programs such as Elderhostel and Learning in Retirement Institutes (LRIs) have drawn substantial numbers of older learners to participate in university-sponsored educational programs. Indeed, the number of older adults who participate in these programs far 
exceeds those who register in tuition-waiver programs. Elderhostel offers more than 10,000 programs a year in over 100 countries (www.elderhostel.org/Programs/programhome.asp). The growing demand for such noncredit educational programs stands in stark contrast to the modest levels of participation by older adults in degree-credit programs.

A number of reports have predicted that with the pending retirement of the "baby boom" cohort in Canada and the United States, we will face shortfalls in many sectors of the workforce. Consequently, there will be both an opportunity and a need for people to remain in the workforce to a later age. Greller and Stroh (1995) reported that workers in the United States aged 55 and older represented only $11.9 \%$ of the workforce in 1995 but by the year 2005 they will represent $15.1 \%$. This is an increase of $27 \%$ in just 10 years. Allen and Hart (1998) reported that by 2025 , nearly $30 \%$ of the entire workforce in the United States will be aged 50 and older. If these projections are accurate it is likely that there will be a significant increase in the number of older adults seeking employmentrelated education and training either through employer-sponsored programs or as self-initiated efforts to maintain professional competence or to prepare for new careers. Anderson (1999) argued that these demographic changes will present higher education institutions with several challenges. One of these challenges will be to provide increased training programs for older adults who want to work. She cited Weaver et al. (1998) as calling for universities and colleges to become more "seniorfriendly" in their policies, services and facilities. Nonetheless, it can be argued that employment-related training for older adults should not be subsidized through tuition-waiver programs.

In summary, these considerations argue for either the outright elimination of tuition-waiver programs, or at least their restriction to older adults with demonstrated financial need. At the same time, they suggest at least two other strategies that should be considered. First, if tuition-waiver programs are eliminated or restricted, institutions might consider the expansion and/or greater promotion of their noncredit offerings to emphasize their continued support for serving the needs of older adults. Second, if greater numbers of older adults seek access to degree-credit studies for employment reasons, and assuming 
that they are paying regular tuition for such programs, consideration should be given to increased student services specific to the needs of older adults.

\section{CONCLUSION}

One of the most compelling conclusions emerging from this study is that tuition-waiver programs are likely to be widely rescinded or restricted in the near future. They have clearly failed to achieve the objective of providing access to those persons for whom tuition fees might be a barrier to participation. Moreover, they have not attracted significant numbers of participants. Dramatic increases in tuition fees together with growing enrolment pressures seriously challenge the continuation of age-based tuition-waiver programs. The recent actions by a number of Canadian universities to eliminate or restrict such programs appear to foreshadow similar action on a wider scale.

More research is warranted on the reasons why relatively few older adults enroll in degree-credit studies. Clearly, it is not due to a lack of interest in learning. The growing popularity of Elderhostel and Learningin-retirement Institutes demonstrates that older adults are strongly interested in educational programs.

\section{Appendix 1: Institutions which have Rescinded (or Modified) Tuition- Waiver Policies}

The University of Alberta introduced a tuition-waiver policy in 1985 that provided for full tuition-waiver for persons aged 65 and older. In 1999 the University rescinded the policy. A recent news release announcing the change reported that the University was concerned about providing free tuition to one segment of the population while fees were increasing for others (http://www.ualberta.ca/folio/9899/01.29/front.html). Moreover, concern was expressed about the growing size of the population aged 65 and older. At the time of the decision, there were 5 seniors enrolled in full-time studies and 28 in part-time studies out of a total student population of approximately 30,000 . 
Brock University has had a tuition-waiver policy for over 20 years that provided full tuition-waiver for persons aged 60 and older. In 1998 (or thereabouts), the University amended their policy to the effect that these persons are expected to pay the full cost of tuition. Nonetheless, those who request the tuition-waiver will still receive one and there is no means test to qualify for the waiver. Experience to date indicates that a few pay the tuition but the majority request the tuition-waiver.

Carleton University introduced a tuition-waiver policy in 1976 which provided that persons aged 60 and older would pay only $\$ 5$ per year. In 2000 , the University amended their policy to the effect that those persons would pay $80 \%$ of the regular tuition. A recent news release from the University indicated that students who cannot afford to pay will not be turned away (http://www.carleton.ca/duc/tic/00/apr03/article5.html). The statement indicated that in 2000 there were 242 students aged 60 and older at Carleton University out of a total student body of approximately 17,000 .

Memorial University of Newfoundland at one time had a tuition-waiver policy that provided full tuition-waiver for persons aged 65 and older. This policy was rescinded some time in the 1990s.

The University of New Brunswick introduced a tuition-waiver policy in 1973 that provided full tuition-waiver for persons aged 60 and older. In 1994 the University rescinded the policy. A recent news release indicated that the University had recently been requested to review this decision and to reinstate the tuition-waiver policy but the request was rejected (http://www.unb.ca/web/ bruns/9696/news/issue 15/seniors.html). The news release identifies a number of reasons for the decision to rescind the tuition-waiver policy including the increasing cost of tuition fees and the increasing number of persons who would be eligible for the tuition-waiver.

Nipissing University introduced a tuition-waiver policy sometime before 1996 which provided full tuition-waiver for persons aged 60 and older. In 1996 the University amended the policy to include a means test. Persons who had a net taxable income of not more than $\$ 25,000$ would receive a bursary equivalent to the cost of tuition.

The University of Ottawa (also includes Saint Paul University) introduced a tuition-waiver policy in 1974 that provided full tuition-waiver for persons aged 60 and older. In 1999, this policy was rescinded.

Queen's University introduced a tuition-waiver policy in 1984 that provided full tuition-waiver for persons aged 65 and older. In 1994 this policy was rescinded. These students may apply for a bursary but a means test is applied to 
determine which students will receive the bursary. The bursary will normally cover the costs of one or two courses each term but bursaries to cover higher course loads will be considered on an individual basis.

Saint Mary's University introduced a tuition-waiver policy in 1979 that provided full tuition-waiver for persons aged 60 and older. In 2000 this policy was rescinded.

The University of Toronto (also includes the University of Saint Michael's College, the University of Trinity College and Victoria University) introduced a tuition-waiver policy in 1975 that provided full tuition-waiver for persons aged 65 and older. In 1992 that policy was rescinded. These students may apply for a bursary but a means test is applied to determine which students will receive the bursary.

Trent University introduced a tuition-waiver policy in 1974 that provided full tuition-waiver for persons aged 65 and older. In 1994 that policy was rescinded. These students may apply for a bursary but a means test is applied to determine which students will receive the bursary.

Trinity Western University had a tuition-waiver policy for a number of years that provided full tuition-waiver for persons aged 65 and older. In 1998 that policy was rescinded. The University will offer special consideration to persons aged 65 and older who are unable to pay full tuition.

The University of Western Ontario (also includes Brescia University College and Huron University College) introduced a tuition-waiver policy in 1974 that provided bursaries equal to the cost of tuition for persons aged 60 and older. In 1994 that policy was rescinded. Bursaries equal to the cost of tuition are still available to these students if they declare that they have financial need of the bursary. No means test is applied however. The student's declaration is sufficient to warrant the awarding of the bursary.

\section{References}

A growing population. (n.d.) http://www.hc-sc.gc.ca/seniors-aines/pubs/ factoids/en/nol.htm.

A report on adult education and training in Canada: Learning a living. (2001). http://www.statscan.ca.

Allen, J. M. \& Hart, M. (1998). Training older workers: Implications for HRD/HPT professionals. Performance Improvement Quarterly, 1/(4), 91-102. 
Anderson, T.B. (1999). Aging education in higher education: Preparing for the 21 st century. Educational Gerontology, 25(6), 571-579.

Bishop-Clark, C \& Lynch, J. (1995). Faculty attitudes toward the mixedage college classroom. Educational Gerontology, 2l(8), 749-761.

Brownstein, A. (2000). Tuition rises faster than inflation, and faster than in previous year. The Chronicle of Higher Education, October 27, A50.

Burd, S. (2001). Lack of need-based financial aid still impedes access to college for low-income students, report finds. The Chronicle of Higher Education, March 2, A26.

Bynum, L.L. \& Seaman, M.A. (1993). Motivations of third-age students in learning-in-retirement institutes. Continuing Higher Education Review, 57 (1\& 2), 12-22.

Chelsvig, K.A. \& Timmermann, S. (1979). Tuition policies of higher educational institutions and state government and the older learner. Educational Gerontology, 4(2), 147-159.

Chelsvig, K.A. \& Timmermann, S. (1982). Support services for older adult tuition programs. Educational Gerontology, 8(3), 269-274.

Cross, K.P. (1981). Adults as learners. San Francisco, CA: Jossey-Bass

Danner, D.D., Danner, F.W. \& Kuder, L.C. (1993). Late-life learners at the university: The Donovan scholars program at age twenty-five. Educational Gerontology, 19(3), 217-239.

Eisen, M-J. (1998). Current practice and innovative programs in older adult learning. In J.C. Fisher \& M.A. Wolf (Eds.), Using learning to meet the challenges of older adulthood, (pp. 41-53). New Directions for Adult and Continuing Education, 77. San Francisco, CA: Jossey-Bass.

Facts about older Americans. (n.d.). http://www.ncoa.org/press/facts.html.

Graney, M.J. \& Hays, W.C. (1976). Senior students: Higher education after age 62. Educational Gerontology, 1(4), 343-359.

Greller, M.M. \& Stroh, L.K. (1995). Careers in midlife and beyond: A fallow field in need of sustenance. Journal of Vocational Behavior, 47(3), 232-247.

Hays, W.C. \& Hays, J.A. (1996). The effect of senior auditors on college classes: An assessment by faculty members. Educational Gerontology, 22(7), 693-709.

Hebel, S. (2001). Public colleges feel impact of the economic downturn. The Chronicle of Higher Education, July 20, A21. 
Heisel, M.A., Darkenwald, G.G., \& Anderson, R.E. (1981). Participation in organized educational activities among adults age 60 and over. Educational Gerontology, 6(2), 227-240.

Hooper, J.O. (1981). Older adults earning university credits: A description. Educational Gerontology, 6(4), 385-394.

Kingston, A.J. (1982). Attitudes and problems of elderly students in the university system of Georgia. Educational Gerontology, 8(1), 87-92.

Kingston, A.J. \& Drotter, M.W. (1983). A comparison of elderly college students in two geographically different areas. Educational Gerontology, 9(5-6), 399-403.

Lamdin, L. \& Fugate, M. (1997). Elderlearning: new frontier in an aging society. Phoenix, AZ: Oryx Press.

Long, H.B. (1980). Characteristics of senior citizens' educational tuition waivers in twenty-one states: A follow-up study. Educational Gerontology, 5(2), 139-149.

Long, H.B. (1983). Analysis of research concerning free and reduced tuition programs for senior citizens. Educational Gerontology, 8(6), 575-584.

Long, H.B. \& Rossing, B.E. (1978). Tuition waivers for older Americans. Lifelong Learning, $1(10), 10-13$.

Long, H.B. \& Rossing, B.E. (1979). Tuition waiver plans for older Americans in postsecondary public education institutions. Educational Gerontology, 4(2), 161-174.

Manheimer, R.J. (1998). The promise and politics of older adult education. Research on Aging, 20(4), 391-414.

Manheimer, R.J.. Snodgrass, D.D., \& Moskow-McKenzie, D. (1985). Older adult education: $A$ guide to research, programs, and policies. Westport, CT: Greenwood Press.

Martin, D.M. \& Lyday, J. (1997). Feelings of loyalty among members of learning-in-retirement programs. Educational Gerontology, 23(4), 315-327.

Merriam, S.B. \& Caffarella, R.S. (1999). Learning in adulthood: A comprehensive guide (2nd ed.). San Francisco, CA: Jossey-Bass.

Midwinter, E. (1983/4). The university of the third age in Britain. Universities Quarterly, 38(1), 9-15.

Minichiello, V. (1992). Meeting the educational needs of an aging population: The Australian experience. International Review of Education, 38(4), 403-416.

Moore, M.L. \& Piland, W.E. (1994). Impact of the campus physical environment on older adult learners. Educational Gerontology, 20(2), 129-138. 
Moyer, I., Jr. \& Lago, D. (1987). Institutional barriers to older learners in higher education: A critique of fee-waiver programs. Educational Gerontology, 13(2), 157-169.

Perkins, H.V. \& Robertson-Tshabo, E.A. (1981). Retirees return to college: An evaluative study at one university campus. Educational Gerontology, $6(2)$, 273-287.

Peterson, D.A. \& Masunaga, H. (1998). Policy for older adult education. In J.C. Fisher \& M.A. Wolf (Eds.), Using learning to meet the challenges of older adulthood (pp. 55-60). New Directions for Adult and Continuing Education, 77. San Francisco, CA: Jossey-Bass.

Romaniuk, J.G. (1983). Educational tuition-waiver policies: A secondary analysis of institutional impact in Virginia. Educational Gerontology, 9(4), 279-292.

Romaniuk, J.G. (1984). Tuition-waiver policies for older adults: What are the assumptions? Educational Gerontology, 10(1/2), 119-133.

Scala, M.A. (1996). Going back to school: Participation motives and experiences of older adults in an undergraduate classroom. Educational Gerontology, 22(8), 747-773.

Thång, P.-O. \& Wärvik, G.-B. (2000). Adult education in Sweden: Possibilities for the middle aged and older people. Education and Aging, 15(1), 49-63.

Tikkanen, T. (1998). The age-participation relationship revised: Focus on older adults. Adult Education Quarterly, 49(1), 15-27. 